\title{
Knit Fabric Scouring with Soapnut: A Sustainable Approach Towards Textile Pre-Treatment
}

\author{
Md. Saiful Hoque ${ }^{1}$, Samit Chakraborty ${ }^{1, ~ *, ~ M d . ~ F o r h a d ~ H o s s a i n ~}{ }^{2}$, Md. Masud Alam \\ ${ }^{1}$ Department of Textile Engineering, Daffodil International University, Dhaka, Bangladesh \\ ${ }^{2}$ Department of Dyes \& Chemicals Engineering, Bangladesh University of Textiles, Dhaka, Bangladesh \\ ${ }^{3}$ Yarn Dyeing Department, Paramount Textile Ltd, Gazipur, Bangladesh \\ Email address: \\ saiful.te@diu.edu.bd(Md. S. Hoque), samit.te@diu.edu.bd(S.Chakraborty), forhad@butex.edu.bd(Md.F. Hossain), \\ masudntex15@gmail.com(Md.M. Alam) \\ ${ }^{*}$ Corresponding author
}

\section{To cite this article:}

Md. Saiful Hoque, Samit Chakraborty, Md. Forhad Hossain, Md. Masud Alam. Knit Fabric Scouring with Soapnut: A Sustainable Approach Towards Textile Pre-Treatment. American Journal of Environmental Protection. Vol. 7, No. 1, 2018, pp. 19-22.

doi: 10.11648/j.ajep.20180701.14

Received: March 20, 2018; Accepted: March 30, 2018; Published: April 26, 2018

\begin{abstract}
Detergent contains amphiphilic molecules which diminish the surface tension of water and are widely used for industrial purpose especially during the pretreatment of fabric. When the wastewater containing industrial detergent is discharged into different water sources, it may cause detrimental effect to the aquatic environment. This research paper focuses on the comparative study of natural detergent (soapnut/reetha) and synthetic detergent in case of $100 \%$ cotton single jersey knit fabric. Experiments were done using the different concentration of soapnut and at $10 \%$ soapnut concentration, weight loss percentage and absorbency of natural detergent scoured fabric were found almost similar to that of fabric scoured with the synthetic detergent. Moreover, bursting strength of fabric scoured with soapnut was found higher than that of synthetic detergent scoured fabric. The result derived from the experiment suggest that soapnut has remarkable detergency properties and can be used as an environment-friendly alternative to synthetic detergent.
\end{abstract}

Keywords: Scouring, Detergent, Soapnut, Sustainability

\section{Introduction}

Textile industry involved with the various processing of fabric which needs the usages of a lot of water along with energy and most importantly harsh chemicals [1]. During the traditional textile processing a fabric needs to go through a lot of treatment like desizing, scouring, mercerization, bleaching, washing etc which is involved with toxic chemicals [2] As Cotton fibre holds about 10\% noncellulosic substance like waxes, pectic substances, organic acids, dust, non-cellulosic polysaccharides, and other unidentified compounds on the outer surface of the fibre, so it becomes the hindrance during fabric processing [3]. The scouring treatment of the fabric removes these impurities completely or partially to make fabric response optimal at the time of bleaching and increase the absorbency of cotton fabric also [4-5]. For the traditional scouring, it needs a lot of synthetic chemicals, which are toxic and detrimental to the environment and human skin also [6]. These chemicals used in pre-treatment have very harsh consequences especially in terms of the high amount of chemical oxygen demand (COD), biological oxygen demand (BOD), $\mathrm{pH}$ and toxicity [7-8]. For that reason, being environment concern researchers are trying to make the textile wet processing eco-friendly and sustainable [9].

\section{Literature Review}

A growing concern has been seen among consumers about sustainable textile manufacturing since last decade. Therefore, manufacturers are developing different viable processes to ensure an eco-friendly production environment [10]. As a part of sustainable textile manufacturing, different researchers have investigated the alternative methods of 
traditional fabric processing technologies. These research included how people can use products extracted from natural sources, while pre-treating (e.g. scouring, bleaching and desizing) and dyeing the textile fabric. Nielsen et al. used enzyme to wash the textile fabric in a sustainable way [11]. According to Chakraborty, manufacturers are working on using environment-friendly products in order to reduce the consumption of harmful chemicals during and prior to the coloration of the fabric [12]. Bio-enzymes, Soapnut and, PyagiPhool are now considered as the best substitute of toxic chemicals used for scouring or washing textile fabric. All of these products are eco-friendly and have good surface-active properties. While comparing these natural surfactants to commercially used anionic surfactant it has been found that the former performs as good as the later [13]. Using soapnut natural fabric scouring can be also helpful in maintaining BOD and COD of waste-water to a tolerable level [14]. Soapnut has been used as an ingredient of shampoo and for cleaning wool fibers for many years [15]. It shows better surface tension reduction and cleansing property compared to Pyagi Phool and the anionic surfactant. Moreover, it has good foaming power and creates stable emulsion at higher concentration [13]. Basu et al. investigated that soap nut can be an efficient and cheaper alternative to synthetic surfactant, having moderate critical micelle concentration [16]. Muntaha and Khan also described natural surfactant as non-toxic, biodegradable and exhibit efficiency over a wide range of temperature, $\mathrm{pH}$, and salinity [15]. Deshmukh and Bansal successfully also proved the improved tearing strength and color fastness properties of cotton woven fabric scoured with soapnut [17]. Besides, synthetic detergents may cause knit fabrics having poor mechanical properties [18]. Such results have led the authors to assess the efficacy of soapnut as a scouring agent and check the bursting strength of the knit fabric scoured with soapnut. Then these measurements were compared with the measurements of knit fabric scoured with the synthetic detergent.

\section{Materials \& Methods}

\subsection{Experimental}

\subsubsection{Fabric and Chemicals}

Grey plain single jersey cotton knitted fabric was used in this experiment. The fabric contained 200 GSM (Grams $/$ Meter $^{2}$ ) having yarn count 16/1 Ne with 286 Kpa strength. Caustic Soda (Sodium Hydroxide, MARCEL Pvt. Ltd., India) was used as a scouring agent for the recipe. Sapindus emarginatus vhal (Soapnut) was used as a natural detergent and Ferrol IPC, Srilanka was used as a synthetic detergent during the experiment while Securon 28A (Pulcra Chemicals, Shanghai, China 2.) and Iscour Jet Conc (ICS Chemicals, Canada)were used besides caustic soda in scouring as sequestering agent and wetting agent respectively.

\subsubsection{Scouring with Sapindus Emarginatus Vhal (Soapnut)}

Scouring of grey knit fabric was carried out in a bath containing different concentration of Sapindus emarginatus
vhal/Soapnut $(2 \%, 4 \%, 6 \%, 8 \%$ and $10 \%)$ powder, $5 \mathrm{gm} / 1$ Caustic soda, $2 \mathrm{gm} / 1$ sequestering agent and $1 \mathrm{gm} / 1$ wetting agent for 40 minute. The temperature of the bath was kept at boiling keeping $\mathrm{M}: \mathrm{L}$ as 1:10 with constant fabric liquor movement

\subsubsection{Scouring with Synthetic Soap (Ferrol IPC)}

Scouring of grey knit fabric was also carried out in a bath containing $5 \%$ synthetic detergent, $5 \mathrm{gm} / 1$ caustic soda, 2 $\mathrm{gm} / 1$ sequestering agent and $1 \mathrm{gm} / 1$ wetting agent for 40 minutes. The temperature of the bath was kept at boiling keeping M: L as 1:10 with constant fabric liquor movement.

\subsection{Scouring Procedure}

At first sample and stock solution were prepared according to the recipe. Then the stock solution was taken into a bath and rest water added into the bath. Then the prepared sample was immersed into the bath. The bath was set into the machine and run 40 minutes at $95^{\circ} \mathrm{C}$. Then the sample was collected from bath and hot wash was done for 10 minutes. After hot wash, the cold wash was also done normally. Finally, the sample was dried by dryer machine.

\subsection{Testing Methods}

The scoured knit fabrics were conditioned in $65 \% \mathrm{RH}$ and $20^{\circ} \mathrm{C}$ for 24 hours before testing according to BS EN 20139 and ASTM D1776 [19]. Weight change (\%) in fabric / GSM was calculated from the difference in fabric weight before and after the treatment. For absorbency test, immersion test, drop test, and spot test were performed. For immersion test, a sample of $(1 \times 1) \mathrm{cm}^{2}$ size was cut and it was left on the water surface. With the help of a stopwatch, the time of the fabric immersion was recorded. For drop test, in a pipette reactive dye is taken and reactive dye was dropped on the fabric and the absorption of the reactive dye drop was observed visually. Times of three drops were taken for each sample and meantime was calculated. And for spot test, In a pipette, a solution of $1 \%$ direct red (Congo red) was taken and the droplet of solution put on the different places of the fabric. Then the shape of the absorption area on the fabric was observed. In order to investigate the mechanical properties, bursting strength, fabric GSM and stitch density (wales per inch and course per inch) were calculated before and after scouring with both synthetic detergent and soapnut. Bursting test was done by following ISO 13938-2 method [20]. The fabric samples (grey, and scoured with detergent and soapnut) were cut by gsm cutter in order to compare the gsm of the fabrics. Finally, the costing of both scouring processes was compared to find out the economical method.

\section{Results and Discussions}

\subsection{Determination of Weight Loss}

Due to scouring fabric losses some weight. The weight loss \% was calculated for both of the fabric samples scoured with Ferrol IPC and soapnut respectively. 
Table 1. Weight loss comparison between soapnut and Ferrol IPC.

\begin{tabular}{lll}
\hline Surfactant & Concentration & Weight loss \% \\
\hline Ferrol IPC & $5 \%$ & 1.41 \\
& $2 \%$ & 1.06 \\
& $4 \%$ & 1.14 \\
Soapnut & $6 \%$ & 1.25 \\
& $8 \%$ & 1.37 \\
& $10 \%$ & 1.47 \\
\hline
\end{tabular}

From the aforementioned table, it can be observed that the weight $\operatorname{loss} \%$ of knit fabric scoured with $2 \%, 4 \%, 6 \%$ and $8 \%$ soapnut was less than the weight $\operatorname{loss} \%$ of the fabric scoured with synthetic detergent. But the weight loss percentage for knit fabric, scoured with $10 \%$ soapnut was greater than the weight loss \% found from the knit fabric scoured with synthetic detergent. It implied that at higher concentrations soapnut performs almost as same as or better than synthetic detergent.

\subsection{Evaluation of Absorbency Test}

Absorbency test was conducted based on three different tests namely- immersion test, drop test and spot test.

\subsubsection{Immersion Test}

Immersion test was done to determine the time that the fabric needed to be immersed into water.

Table 2. Immersion time comparison between soapnut and synthetic detergent.

\begin{tabular}{lll}
\hline Surfactant & Amount & Immersion time (Sec) \\
\hline Ferrol IPC & $5 \%$ & 5 \\
& $2 \%$ & 15 \\
& $4 \%$ & 12 \\
Soapnut & $6 \%$ & 10 \\
& $8 \%$ & 7 \\
& $10 \%$ & 3 \\
\hline
\end{tabular}

The data presented in table 2 showed that a fabric scoured with Ferrol IPC took 5 seconds to be immersed into water. On the other hand, fabric scoured with $2 \%, 4 \%, 6 \%$ and $8 \%$ soapnut took 15, 12, 10 and 7 seconds respectively to be immersed into water. But fabric scoured with $10 \%$ soapnut took less immersion time than that of the fabric scoured with the synthetic detergent.

\subsubsection{Drop Test}

Drop test is done to determined how much time the fabric needed to absorb a drop of solution made of direct dye and water.

Table 3. Drop test comparison between soapnut and Ferrol IPC.

\begin{tabular}{lll}
\hline Surfactant & Amount & Drop absorbing time(Sec) \\
\hline Ferrol IPC & $5 \%$ & 0.8 \\
& $2 \%$ & 6 \\
& $4 \%$ & 4 \\
Soapnut & $6 \%$ & 3 \\
& $8 \%$ & 1 \\
& $10 \%$ & 0.7 \\
\hline
\end{tabular}

From the table 3 it could be discussed that the fabric sample scoured with Ferrol IPC took 0.8 seconds to absorb the drop. On the other hand, the fabric sample scored with soapnut took $6,4,3,1$ and 0.7 seconds to absorb the drop of the solution, which implied that soapnut performed better scouring in higher concentration when compared with the performance of fabric scoured with synthetic detergent.

\subsubsection{Evaluation of Spot Test}

Spot test was conducted to determine the scouring performance based on the visual assessment of the dye spots on the fabric. From the spot test it was deducted that there was uniform scouring for the fabric scoured with 5\% Ferrol IPC detergent and fabric scoured with $6 \%$ and $8 \%$ soapnut. But there was uneven scouring while fabric was scoured with $2 \%$ and $4 \%$ soapnut. On the other hand, fabric scoured with $10 \%$ soapnut showed uniform scouring. Therefore, it can be concluded higher concentration of $(10 \%)$ soapnut can make fabric cleaner than that of the synthetic detergent.

\subsection{GSM Measurement}

Loss of weight of the pre-treated samples is an important factor of pre-treatment as it is related to next subsequent process of the fabric. The weight loss which is determined after scouring by both natural and synthetic detergent is shown in the table.

Table 4. GSM comparison between soapnut and Ferrol IPC.

\begin{tabular}{llll}
\hline \multirow{2}{*}{$\begin{array}{l}\text { Grey } \\
\text { GSM }\end{array}$} & $\begin{array}{l}\text { GSM after scouring } \\
\text { with 5 \% synthetic } \\
\text { detergent }\end{array}$ & $\begin{array}{l}\text { GSM after scouring with Natural } \\
\text { detergent }\end{array}$ \\
\cline { 3 - 4 } & & $\begin{array}{l}\text { Natural detergent } \\
\text { concentration }\end{array}$ & GSM \\
\hline & $2 \%$ & 190 \\
200 & \multirow{2}{*}{186} & $4 \%$ & 188 \\
& & $6 \%$ & 187 \\
& & $8 \%$ & 184 \\
& $10 \%$ & 185 \\
\hline
\end{tabular}

As per the gsm measurement the initial grey fabric gsm was found as 200. After the scouring treatment with Ferrol IPC synthetic detergent the fabric gsm came down to 186 . On the other hand, the gsm found for different concentrations of soapnut were $190,188,187,184$ and 185 respectively (shown in table 4). These results implied that the fiber loss or gsm drop was higher in case of using 5\% synthetic detergent, $8 \%$ and $10 \%$ soapnut than that of the fabric while treated with $2 \%, 4 \%$ and $6 \%$ soapnut.

\subsection{Bursting Strength}

Table 5. Bursting strength comparison between soapnut and Ferrol IPC.

\begin{tabular}{llll}
\hline $\begin{array}{l}\text { Bursting } \\
\text { strength }\end{array}$ & $\begin{array}{l}\text { Bursting strength } \\
\text { after scouring with }\end{array}$ & $\begin{array}{l}\text { Bursting strength after scouring } \\
\text { with Natural detergent }\end{array}$ \\
\cline { 3 - 4 } fabric & $\mathbf{5 \% \text { synthetic }}$ & $\begin{array}{l}\text { Natural detergent } \\
\text { concentration }\end{array}$ & $\begin{array}{l}\text { Bursting } \\
\text { Strength }\end{array}$ \\
\hline & & $2 \%$ & 283 \\
& & $4 \%$ & 281 \\
$286 \mathrm{Kpa}$ & 276 & $6 \%$ & 280 \\
& & $8 \%$ & 279 \\
& & $10 \%$ & 277 \\
\hline
\end{tabular}

The bursting strength of the grey knit fabric was found 286 
Kpa while after treating with synthetic detergent came down to 276 . In case of treatment with the natural detergent better result was found, which might happen due to the loss of less fibre and strength. From the table it could be deducted that with the increase of the concentration of soapnut bursting strength decreased but was still higher than that of the fabric while treated with synthetic detergent.

\subsection{Costing}

As per the price of the detergent used in scouring manufacturer need to spend $\$ 1.56$ for scouring $1 \mathrm{~kg}$ of $\mathrm{knit}$ fabric. On the other hand, $1 \mathrm{~kg}$ of soapnut is available in the market at a price of $\$ .70$. So, it can be stated that using soapnut in scouring is a cheaper alternative to industrial detergent.

\section{Conclusion}

The research showed that soap nut could be a sustainable and cheaper alternative to synthetic detergent in knit fabric scouring method. However, higher concentration of soap nut should be used in order to get the better performance compared to detergent. Different properties of fabric- gsm, course density and bursting also altered to a little extent when it is scoured with soapnut than that of scoured with detergent. The weight loss percentage, drop test and spot also exhibited that higher concentration of soapnut could ensure better scouring performance than industrial detergent. The future researches in this topic can assess the whiteness index of fabric scoured with natural surfactant. Moreover, researchers can investigate the performance of such natural surfactant on fabrics of other constructions and compositions.

\section{References}

[1] Mojsov, K., 2012. Enzyme scouring of cotton fabrics: a review. International Journal of Marketing and Technology (IJMT), 2(9), pp. 256-275.

[2] CHURI, R., KHADILKAR, S. and SULE, S., 2004. Enzyme Systems for processing cellulosic textiles. Colourage, 51(4), pp. 53-56.

[3] Lin, C. H. and Hsieh, Y. L., 2001. Direct scouring of greige cotton fabrics with proteases. Textile Research Journal, 71(5), pp. 425-434.

[4] Li, Y. and Hardin, Z. R., 1997. Enzymatic scouring of cotton: effects on structure and properties. Cellulose, 94(88.0), pp. 960 .

[5] Clark, M. ed., 2011. Handbook of textile and industrial dyeing: principles, processes and types of dyes. Elsevier.
[6] Rocky, A. B. P., Comparison of Effectiveness Between Conventional Scouring \& Bio-Scouring On Cotton Fabrics".

[7] El Shafie, A., Fouda, M. M. and Hashem, M., 2009. One-step process for bio-scouring and peracetic acid bleaching of cotton fabric. Carbohydrate Polymers, 78(2), pp. 302-308.

[8] Hardin, I. R., 2010. Enzymatic treatment versus conventional chemical processing of cotton. In Advances in Textile Biotechnology (pp. 132-149).

[9] Keiner, M., 2005. History, definition (s) and models of sustainable development. ETH Zurich.

[10] Kant, R., Chopra, C. and Sisodia, N. 2017. Need for ecofriendly finished textiles. International Journal of Applied Home Science, 4(7), pp. 634-644.

[11] Nielsen, P. H., Kuilderd, H., Zhou, W. and Lu, X., 2009. Enzyme biotechnology for sustainable textiles. Sustainable textiles. Life cycle and environmental impact, pp. 113-138.

[12] Chakraborty, S., 2016. A Detailed Study on Environmental Sustainability in Knit Composite Industries of Bangladesh. American Journal of Environmental Protection, 5(5), pp. 121127.

[13] Pradhan, A. and Bhattacharyya, A., 2017. Quest for an ecofriendly alternative surfactant: Surface and foam characteristics of natural surfactants. Journal of Cleaner Production, 150, pp. 127-134.

[14] Kherdekar, G. and Adivarekar, R. 2017. Effect of Wool Scouring Technique on Wool Fiber. International Journal of Recent Trends in Engineering and Research, 3(11), pp. 289294.

[15] Muntaha, S. T. and Khan, M. N. 2015. Natural surfactant extracted from Sapindusmukurossi as an eco-friendly alternate to synthetic surfactant-a dye surfactant interaction study. Journal of Cleaner Production, 93, pp. 145-150.

[16] Basu, A., Basu, S., Bandyopadhyay, S. and Chowdhury, R., 2015. Optimization of evaporative extraction of natural emulsifier cum surfactant from SapindusmukorossiCharacterization and cost analysis. Industrial Crops and Products, 77, pp. 920-931.

[17] Deshmukh, A. and Bansal, L. 2018. sapindus emarginatus vahl as a natural scourung agent in dyeing of cotton with carissa carandas leaf extract. Biolife, 2(2), pp. 599-604.

[18] Chiweshe, A. and Crews, P. C., 2000. Influence of household fabric softeners and laundry enzymes on pilling and breaking strength. Textile Chemist and Colorist and American Dyestuff Reporter, 32(9), pp. 41-47.

[19] ASTM D 1776. Standard practice for conditioning textiles for testing. American Society for Testing and Materials, Annual Book of ASTM Standards, vol. 7(1). ASTM International, West Conshohocken, PA, USA, 2008.

[20] ISO, B. (1999). 13938-2. Textiles-Bursting Properties of Fabrics, Part, 2. 